\title{
O Psicólogo e a Inclusão de Pessoas com Deficiência no Trabalho
}

\author{
Mário Lázaro Camargo \\ Universidade Estadual Paulista \\ "Júlio de Mesquita Filho", Bauru, SP, Brasil. \\ Edward Goulart Júnior \\ Universidade Estadual Paulista \\ "Júlio de Mesquita Filho", Bauru, SP, Brasil. \\ Lúcia Pereira Leite \\ Universidade Estadual Paulista \\ "Júlio de Mesquita Filho", Bauru, SP, Brasil.
}

\begin{abstract}
Resumo: Mediante pesquisa bibliográfica realizada nas principais bases de dados disponíveis atualmente, este ensaio discute a situação atual da inclusão de pessoas com deficiência no mercado de trabalho, destacando os obstáculos e desafios presentes na realidade brasileira. Discute ainda a atuação do Psicólogo Organizacional e do Trabalho (POT) neste contexto, postulando sobre a importância de seu comprometimento com as transformações necessárias, tanto na sociedade quanto nas organizações de trabalho, para que tenhamos uma cultura verdadeiramente inclusiva. Embora essa temática venha sendo amplamente discutida, o presente estudo concluiu que ainda temos muito a avançar, considerando, sobretudo, as questões culturais que, somadas ao despreparo das organizações e dos gestores organizacionais para lidarem com os trabalhadores com deficiência, representam os maiores obstáculos à inclusão. Embora devamos reconhecer que no Brasil houve avanços, em especial após a promulgação, em 1991, da chamada Lei de Cotas, diversas pesquisas têm apontado para a dificuldade, por parte das organizações, em cumpri-la. Entendemos que o POT deva ser um profissional preparado técnica e eticamente para, juntamente com outros profissionais, promover ações na direção de um processo efetivo de inclusão dessa população nos contextos de trabalho, favorecendo não somente as pessoas envolvidas, como também, as próprias organizações.
\end{abstract}

Palavras-chave: Inclusão, Pessoas com Deficiência, Psicologia Organizacional e do Trabalho.

\section{The Psychologist and the Inclusion of People with Disabilities at Work}

\begin{abstract}
Through bibliographical research carried out in the major databases available today, this paper discusses the current situation of inclusion of people with disabilities in the labor market, highlighting present obstacles and challenges in the Brazilian reality. It also discusses the role of the Work and Organizational Psychologists (WOP) in this context, suggesting the importance of their commitment to the necessary changes, both in society and work organizations, so that we have a truly inclusive culture. Although this theme has been widely discussed, the study found that we still have long way to go, considering all the cultural issues that, added to the unpreparedness of organizations and organizational managers to deal with employees with disabilities, represent major obstacles to inclusion. While we must recognize that there has been progress in Brazil, especially after the promulgation in 1991 of the so-called "Quota" Law, several studies have pointed to the difficulty of organizations in fulfilling it. We understand that theWOP should be a ethically and technically prepared professional for, along with other professionals, promoting actions towards an effective process of inclusion of this population in the contexts of work, not only favoring the people involved, but also the organizations.
\end{abstract}

Keywords: Inclusion, People with Disability, Work and Organizational Psychology. 


\title{
El Psicólogo y la Inclusión de las Personas con Discapacidad en el Trabajo
}

\begin{abstract}
Resumen: Mediante investigación bibliográfica realizada en las principales bases de datos disponibles hoy, este trabajo analiza la situación actual de la inclusión de personas con discapacidad en el mercado laboral, poniendo de relieve los obstáculos y desafíos presentes en la realidad brasileña. También se discute el papel del Psicólogo Organizacional y del Trabajo (POT) en este contexto, resaltando la importancia de su compromiso con los cambios necesarios en la sociedad y en las organizaciones para que tengamos una cultura verdaderamente incluyente. Aunque este tema venga siendo ampliamente discutido, el estudio encontró que todavía nos queda mucho camino por recorrer, considerando especialmente las cuestiones culturales que, añadidas a la falta de preparación de las organizaciones y los gerentes de la organización para hacer frente a los empleados con discapacidad, representan los principales obstáculos a la inclusión. Si bien hay que reconocer que en Brasil se han registrado avances, especialmente después de la promulgación en 1991 de la llamada Ley de Cuotas, varios estudios han señalado la dificultad de las organizaciones en cumplirla. Entendemos que el POT debe ser un profesional técnica y éticamente preparado, junto con otros profesionales, para promover acciones hacia un proceso efectivo de inclusión de esta población en los contextos de trabajo, favoreciendo no solo a las personas involucradas, sino también a las organizaciones.
\end{abstract}

Palabras clave: Inclusión, Personas con Discapacidad, Psicología Organizacional y del Trabajo.

\section{Introdução}

O presente artigo resulta dos estudos, observações e reflexões dos autores em relação ao contexto aqui intitulado "inclusão de pessoas com deficiência no trabalho", em particular sobre como a atuação do Psicólogo Organizacional e do Trabalho (POT) pode contribuir para que ocorram transformações qualitativamente necessárias. Tais mudanças visam promover o desenvolvimento de uma cultura de inclusão na sociedade e nas organizações, posto que as constatações - como adiante apresentaremos - sinalizam para um cenário de pouca e lenta evolução, ou seja, ainda são muitas as pessoas com deficiência que, no Brasil, se encontram excluídas do mercado de trabalho, assim como também de outras esferas sociais.

Este artigo classifica-se como ensaio teórico, e por meio dele objetiva-se apresentar a situação atual da temática "inclusão de pessoas com deficiência no trabalho", considerando os obstáculos vividos pela sociedade brasileira no enfrentamento dos desafios por se ampliar as oportunidades de participação desse segmento no mercado de trabalho, como também discutir sobre a atuação do POT nesta questão, ou seja, ao longo do texto defende-se a ideia de que este contexto representa um espaço importante para a atuação deste profissional, podendo ser ele um ator social com grandes responsabilidades e de significativa relevância no processo de transformação da, ainda vigente, cultura de exclusão de grupos minoritários, como no caso aqui retratado, tanto no nível mais amplo - sociedade quanto no nível das organizações de trabalho.

Para alcançar os objetivos propostos neste ensaio teórico, os autores apoiaram-se nos resultados de uma revisão da literatura nacional, realizada mediante consulta às bases de dados: Index - Psi Periódicos (CFP); Lilacs (Bireme); Clase - Citas Latinoamericanas em Ciências Sociales y Humanidades; Latindex - Sistema Regional de Información en Línea para Revistas Científicas de América Latina, el Caribe, España y Portugal; SciELO - Scientific Electronic Library Online; Psicodoc - Base de Dados Bibliográfica de Psicologia; BVS-Psi Brasil, buscando estabelecer um diálogo com a comunidade científica que, nas últimas décadas, tem igualmente se debruçado sobre essa temática.

Este texto traz para o debate a reapresentação de uma pauta relevante para o desenvolvimento da Psicologia enquanto Ciência e Profissão no Brasil, indicando a necessidade de uma reavaliação e, em alguns casos, talvez de uma reformulação, de diretrizes curriculares e projetos pedagógicos de cursos de formação de psicólogos que, por ventura, ainda desconsideram a temática como digna de atenção e suficiente espaço, seja sob a forma de disciplinas teóricas e estágios básicos ou pro- 
fissionalizantes, ou sob a forma de projetos de pesquisa e/ou extensão universitária. Essa defesa permitirá o desenvolvimento, nos futuros psicólogos, de uma sensibilidade crítica e compromisso com o tema, desde seu processo formativo até seu exercício profissional.

Os apontamentos a seguir apresentados sinalizam, nesse sentido, para a necessidade de um olhar cuidadoso para os processos formativos de profissionais que atuam na área de Gestão de Pessoas (uma área que exige atuação multiprofissional: administradores de empresa, advogados, economistas, assistentes sociais, médicos do trabalho, engenheiros de produção, pedagogos etc.) nas organizações de trabalho - em que também se inclui o POT, posto que o despreparo destes profissionais pode se apresentar como um dos obstáculos à inclusão de pessoas com deficiência no mercado de trabalho.

A estrutura deste ensaio é pautada no seguinte percurso textual: primeiramente um olhar para a deficiência e suas formas de tratamento ao longo da história, com a finalidade de justificar os motivos pelos quais esta parcela da população ainda é alvo de preconceitos e de tratamentos discriminatórios na sociedade atual; em seguida, um olhar para o cenário atual da questão "inclusão da pessoa com deficiência no trabalho", de forma a dar visibilidade à pertinência da discussão; na sequência, realiza-se uma apresentação das vigentes legislações, em especial a Lei de Cotas, e suas implicações sobre o tema da inclusão de pessoas com deficiência no mercado de trabalho brasileiro, objetivando promover uma compreensão sobre as motivações que as organizações passaram a ter quando buscam contratar este público; encaminhando o texto para seu desfecho, segue-se uma explanação sobre o POT, sua identidade e desafios frente ao tema, identificando o nexo relacional entre seu status científico-profissional e a questão "inclusão da pessoa com deficiência no trabalho"; e, por último, nossas considerações finais propositivas, em que apresentamos algumas reflexões sob a forma de desafios lançados ao processo formativo e de exercício da profissão do psicólogo junto às pessoas com deficiência nas organizações de trabalho.

\section{A pessoa com deficiência e o trabalho: considerações sobre o cenário brasileiro}

A forma com que a sociedade tem se relacionado com as pessoas com deficiência $(\mathrm{PcD})$ vem sofrendo transformações ao longo da história, principalmente no que se refere ao conjunto dos saberes e práticas que permeiam essa relação. De acordo com Assunção, Aranha (2001), Carvalho-Freitas e Oliveira (2015), Correr (2010) e Rocha (2000), para se compreender o modo como a sociedade concebe as PcD, é necessário revisitar a história e analisar as premissas culturais de épocas distintas, de forma que seja possível compreender as concepções relacionadas às diferenças humanas, as quais repercutem até os dias atuais nos modelos de atendimentos institucionais dirigidos a elas e, principalmente, no que diz respeito à manutenção dos, ainda fortemente presentes, preconceitos e mitos relacionados à condição de "anormalidade" - modo como muitos se referem à constituição física, mental ou psicológica das pessoas com deficiência.

Sinteticamente, Amiralian (1986), Aranha (2001) e Figueira (2015) apontam que, na Idade Antiga e Idade Média, as pessoas consideradas defeituosas eram literalmente eliminadas, pois aos olhos da sociedade elas não possuíam qualquer utilidade para o trabalho, e, portanto, não poderiam contribuir para o desenvolvimento das comunidades. Com o advento do cristianismo, começa a se disseminar a ideia de que a deficiência era um castigo decorrente dos pecados cometidos por seus genitores ou consequência de uma possessão demoníaca; o que, segundo Amiralian (1986), Dota (2015) e Figueira (2015), caracterizou-se como uma explicação metafísica e religiosa do fenômeno da diferença humana.

Segundo os mesmos autores, nos séculos XVI e XVII, em virtude das várias mudanças ocorridas nas formas de produção e organização do trabalho, também se verificaram importantes transformações no modo como a sociedade se relacionava com as pessoas com deficiência - aspectos esses que fundamentaram a segregação das mesmas em instituições asilares, cujo objetivo era tratá-las e educá-las, definindo-se, neste período da história, o chamado "Paradigma da Institucionalização". Nessa perspectiva, as pessoas eram afastadas do convívio comum e dificilmente retornavam aos seus lares de origem. Nas palavras de Marques (1998, p. 112), este processo "só fez fortalecer ainda mais o estigma da inferioridade" das pessoas com deficiência, que passaram a ser vistas como condenadas ao isolamento dos asilos, das clínicas, dos educandários, ou seja, fadadas a uma marginalizada institucionalização.

Posteriormente, surge o "Paradigma de Serviços", que representou um avanço comparado ao primeiro, pois buscou proporcionar às pessoas com deficiência uma vida mais próxima da normalidade (Aranha, 2001). No entanto, o principal objeto de intervenção 
pró-mudança era o indivíduo deficiente, ou seja, ele deveria se adaptar à sociedade, seus contextos e regras, a partir da busca pela normalização, estando ainda embutida aí a crença de que a diferença é, por si só, negativa.

Contudo, ao se conceber uma sociedade acessível a todos, seria necessária a mudança no foco da atenção, pois, até então, a pessoas com deficiência é que deveriam ajustar-se ao meio para acessar os bens e serviços disponíveis em uma dada cultura. No momento atual a relação da sociedade com as pessoas com deficiência está pautada (ou deveria estar) nos princípios do "Paradigma de Suportes", que buscou reconhecer a diversidade como parte da natureza humana e em função disso cabe à sociedade garantir o direito das pessoas com deficiência para que tenham acesso a todos os recursos disponíveis por intermédio de ações que favorecessem a sua participação nas mais variadas instâncias (trabalho, saúde, educação, lazer, entre outras) (OEA, 1999). Tal movimento torna clara a responsabilidade do meio social na provisão de suportes físicos, psicológicos, sociais e instrumentais para garantir a participação de quaisquer indivíduos, deficientes ou não, na vida comunitária. Nessa direção, tal paradigma concretiza a ideia de intervenções individuais, mas em igual medida também na sociedade sustentado o movimento da inclusão social.

Numa alusão histórica, Rocha (2000) relata que, do ponto de vista da moral moderna, é possível observar avanços, ainda que graduais, na forma como a sociedade vem lidando com o fenômeno da deficiência. É perceptível ao longo da história que o modo como a sociedade interpreta a deficiência e se relaciona com as pessoas sob esta condição, passou por diversas alterações até chegar ao formato atual. Entretanto, o tema da inclusão social é ainda recente, carente de atenção e da efetivação das políticas públicas que orientam mudanças contextuais. Com isso, até o presente momento, a temática da inclusão social - tida como complexa e polêmica - tem suscitado diversas discussões entre os profissionais que atuam na área da saúde, da educação e do trabalho.

\section{A PcD e o trabalho: considerações sobre o cenário brasileiro}

O termo "inclusão social", conforme descrito por Omote (2008), não desconsidera a necessidade de capacitação das pessoas com deficiência para o convívio social e o desempenho de diferentes papéis na comunidade, porém, a fim de que o processo de inclusão ocorra satisfatoriamente, é necessário que a sociedade se ajuste para acolher o deficiente, oferecendo-lhe suportes suficientes (social, econômico, físico e instrumental) para o acesso e a convivência no espaço comum. Nesse sentido a inclusão passa a ser entendida como um processo interativo, bidirecional, em que se realizam intervenções junto ao indivíduo, a título de qualificá-lo, e junto ao contexto social (e organizacional), para torná-lo acessível, e assim melhor viabilizar a participação de todos.

Por inclusão social, devemos entender a possibilidade da pessoa com deficiência - aliás, de todo cidadão - vivenciar uma efetiva participação na vida social, econômica, cultural e política dos contextos micro, meso e macro de sua inserção, tendo respeitados os seus direitos, independentemente de sua classe social, raça, religião, sexo etc. (Camargo, 2014). Contudo, segundo Carvalho-Freitas, Marques e Almeida (2009) e Tanaka e Manzini (2005), uma questão que tem incitado divergências é o processo de participação dessas pessoas no mercado de trabalho. Tal fato começou a ser considerado dentro das organizações, principalmente a partir da aprovação de ações afirmativas do Estado, sob a forma de leis, que tentam assegurar esse direito - como a Lei de Cotas, da qual trataremos mais adiante.

Ao se falar em inclusão social, especialmente na participação das pessoas com deficiência nos âmbitos organizacionais de trabalho, se faz importante compreender que as relações de trabalho na atualidade sofrem profundas modificações, tanto no que tange à chegada cada vez mais acentuada de novas tecnologias, como também na busca constante de novas formas de produção. Diferentes maneiras de organização do trabalho se apresentam, acentuando a interdependência no trabalho e a valorização do trabalho coletivo (Borges, \&Yamamoto, 2004; Camargo, 2014; Correr, 2010). Nesse contexto atual, as pessoas precisam se adaptar aos novos processos de trabalho que, segundo Del Prette e Del Prette (2008) e Puente-Palacios e Albuquerque (2014), mais do que nunca, remetem diretamente às relações interpessoais, com maior valorização do trabalho em equipe, da criatividade, da intuição e da autonomia nas tomadas de decisões.

O mundo do trabalho, cada vez mais exigente e competitivo, passou a valorizar, além das competências técnicas dos trabalhadores, também suas competências humanas, sobretudo aquelas relacionadas 
às habilidades de interação. De acordo com Araújo e Schmidt (2006) e Bernal (2010), a globalização impulsiona a exigência cada vez maior por profissionais mais capacitados, adaptáveis e ágeis, tanto no que se refere à escolarização quanto à especialização profissional. Ainda segundo estes autores, um dos mais graves problemas que caracteriza o contexto de trabalho na atualidade é o desemprego de uma grande parcela da população que, consequentemente, acaba sendo excluída socialmente. Tal problemática decorre da enorme dificuldade dos países em desenvolvimento, dentre eles o Brasil, de tornar disponíveis para todos, condições satisfatórias e equânimes de saúde, educação e assistência social. Essa dificuldade culmina com a imposição de barreiras para que essas pessoas consigam ter acesso ao mercado de trabalho, promovendo então a exclusão de segmentos populacionais diversos, em especial, das pessoas com deficiência. Entretanto, para Miranda (2006), o fato do indivíduo apresentar qualquer espécie de dificuldade, seja ela intelectual, visual, auditiva ou de locomoção, não deveria se constituir como um aspecto impeditivo para fazer parte do processo produtivo, uma vez que deveriam ser garantidas a esse mesmo indivíduo condições para o desenvolvimento do processo de cidadania.

Em consulta à literatura pertinente, constata-se que a elaboração de propostas voltadas a promover a participação desse segmento no mercado de trabalho tem se constituído como uma prática dentro das organizações a partir da vigência do Decreto no 3.298/1999 (BRASIL, 1999), que regulamenta a Lei $\mathrm{n}^{\circ} 7.853$, de 24 de outubro de 1989, que dispõe sobre a Política Nacional para a Integração da Pessoa Deficiente e estabelece o compromisso do Estado com a formação profissional da pessoa com deficiência, com sua qualificação profissional e seu ingresso no mercado de trabalho. Esse fato suscitou diversas reflexões e algumas pesquisas na área, a fim de constatar quais variáveis tornam esse processo tão complicado e vagaroso para sua implantação.

Bittencourt e Fonseca (2011), Dota (2015) e Tanaka e Manzini (2005), apontam que, no Brasil, a formação profissional das pessoas com deficiência ainda é realizada predominantemente por instituições de Educação Especial, as quais se utilizam de programas elaborados mais em função dos recursos materiais disponíveis (na maioria das vezes parcos), em vez de demandas e exigências presentes atualmente nos contextos de trabalho, além do que, algumas ainda atuam na já ultrapas- sada perspectiva assistencial (Camargo, 2014; Figueira, 2015). Os referidos autores argumentam que a baixa qualificação profissional é um dos principais pontos impeditivos para a contratação dessa parcela da população. Não obstante a este fato, constata-se também, segundo Carvalho-Freitas e Marques (2009), outro elemento importante a ser considerado: o despreparo dos empregadores e de outros profissionais atuantes nas organizações para receberem esse contingente populacional no ambiente de trabalho, em especial aqueles relacionados à área de Gestão de Pessoas. Na mesma perspectiva, entende-se que a cultura organizacional se configura como fator dificultador para a recepção nos contextos de trabalho, uma vez as instâncias corporativas coadunam com preceitos existentes na sociedade em geral, em que a desinformação em relação às deficiências e preconceitos cristalizados ainda prevalecem.

Em pesquisa que visou levantar dados em empresas e instituições que atendem pessoas com deficiência, Araújo e Schmidt (2006) relatam que ações têm sido colocadas em prática para promover a inclusão no mercado de trabalho e as eventuais dificuldades encontradas. Constataram que a falta de informação, por parte das pessoas que atuam nas organizações, com relação às deficiências se constitui como um dos aspectos que as fazem ressaltar apenas as dificuldades apresentadas. No estudo, $20 \%$ das empresas investigadas afirmaram contratar pessoas com deficiência apenas para cumprirem a obrigatoriedade legal, sem de fato estarem comprometidas com o processo efetivo de inclusão social; fato este corroborado nos estudos de Camargo (2014). Correr (2010), Hansel (2009), Vieira, Vieira e Francischetti (2015) e Violante e Leite (2011). Outra constatação importante diz respeito à falta de escolarização e à baixa qualificação profissional que se constituem como grandes fatores impeditivos para a contratação deste público, uma vez que a exigência educacional, para a maioria das empresas participantes da pesquisa, era o ensino fundamental completo; estes achados apresentam-se igualmente nos trabalhos de Bittencourt e Fonseca (2011), Correr (2010), Dota (2015) e Nascimento e Miranda (2007).

Já a pesquisa realizada por Carvalho-Freitas (2009) buscou identificar a relação entre a concepção de deficiência, as práticas de adequação para a inserção da pessoa com deficiência nas empresas e as pessoas responsáveis por tal processo, e revelou que são múltiplas as concepções de deficiência apresentadas pelos indivíduos pesquisados. Outro ponto desta- 
cado na pesquisa refere-se à priorização de modificações nas condições físicas do ambiente de trabalho, em detrimento de ações de sensibilização e práticas de Gestão de Pessoas, que, de fato, promoveriam de modo mais efetivo a participação plena destas no contexto organizacional de trabalho.

Diante das considerações apresentadas, verifica-se que são diversos os fatores que influenciam o modo como ocorre a inserção das pessoas com deficiência no contexto de trabalho, indicando a necessidade de implantar ações que convirjam com a participação efetiva desse segmento populacional, o qual vem se revelando expressivo. De acordo com Censo Demográfico 2010 - Resultados Gerais da Amostra - realizado pelo Instituto Brasileiro de Geografia Estatística (IBGE, 2010), o contingente de pessoas com alguma deficiência no Brasil era de 45,6 milhões, com comprometimento em pelo menos uma das deficiências investigadas (visual, física, auditiva e intelectual), que em termos percentuais representava $23,9 \%$ do total da população do país e desse montante 12,7 milhões de pessoas disseram ter alguma deficiência severa. Na leitura deste documento observa-se que, mesmo com políticas funcionado como uma válvula impulsionadora para a abertura de vagas nas empresas, o número de pessoas com deficiência que ora está participando do mercado de trabalho ainda está muito aquém do planejado, pois ao se pensar em termos de empregabilidade tem-se que em relação ao total da população desocupada ou não economicamente ativa no país $(75,6$ milhões) as pessoas com deficiência representam $31,3 \%$ dessa amostra.

\section{Ações afirmativas pró-inclusão: a Lei de Cotas inclui ou insere?}

Segundo a Declaração Universal dos Direitos do Homem e do Cidadão, resultante da Assembleia Geral das Nações Unidas de 1948, todo homem tem direito ao trabalho, à livre escolha de emprego, às condições justas e favoráveis de trabalho e à proteção contra o desemprego. Por seu turno, desde 1983, a Organização Internacional do Trabalho (OIT) expressa uma preocupação em promover o acesso das pessoas com deficiência ao contexto de trabalho. Na Recomendação $n^{\circ}$ 159/1983 dessa organização (OIT, 1983), do qual o Brasil é signatário, há um item que declara a necessidade de se eliminar toda e qualquer barreira ou obstáculo físico e de comunicação que possam vir a interferir no emprego, treinamento e circulação dessas pessoas nos ambientes de trabalho.
Em termos nacionais, a legislação que busca garantir o acesso das pessoas com deficiência ao mercado de trabalho passou a vigorar há quase duas décadas, com a aprovação de duas leis. A Lei n ${ }^{\circ} 8.112$ (BRASIL, 1990), de 11 de dezembro de 1990, a qual dispõe sobre a reserva até $20 \%$ das vagas em concursos públicos para pessoas que apresentam algum tipo de deficiência e a Lei no 8.213 (BRASIL, 1991), de 24 de julho de 1991 (conhecida como Lei de Cotas), que estabelece uma reserva de vagas nas empresas privadas com mais de 100 trabalhadores - variável entre $2 \%$ a $5 \%$ de acordo com número de trabalhadores da organização.

$\mathrm{Na}$ análise da legislação brasileira, constata-se um investimento em ações que promovam a empregabilidade das pessoas com deficiência, uma vez que os documentos citados asseguram o seu acesso ao contexto laboral, nos âmbitos público e privado. A reserva de vagas para esse segmento em ambos os setores tem gerado amplas discussões, com argumentações tanto favoráveis quanto desfavoráveis, o que evidencia a complexidade do assunto. De um lado há a discussão demonstrando o quanto seria positivo proporcionar o seu convívio em todas as esferas sociais para que o preconceito sociocultural diminuísse, e de outro, há o argumento de que as cotas seriam uma imposição legal, que traria ainda mais preconceito, principalmente no ambiente de trabalho, por se tratar de uma medida privilegiável, garantindo assim uma parcela de vagas para o público mencionado (Correr, 2010; Vieira, Vieira, \& Francischetti 2015).

Por meio do Decreto no 6.949 (BRASIL, 2009), de 25 de agosto de 2009, o Brasil ratificou e promulgou a Convenção Internacional sobre os Direitos das Pessoas com Deficiência, realizada em Nova Iorque em 2007. O texto traz uma mudança no conceito de deficiência, definição também adotada pelo Brasil em seu recente Estatuto da Pessoa com Deficiência (Lei Brasileira de Inclusão - no 13.146, de 6 de julho de 2015), dispondo, em seu artigo $2^{\circ}$, que pessoas com deficiência são aquelas que têm impedimentos de longo prazo de natureza física, mental, intelectual ou sensorial, os quais, em interação com diversas barreiras, podem obstruir sua participação plena e efetiva na sociedade em igualdade de condições com as demais pessoas (BRASIL, 2015). Tal definição é considerada um avanço, pois até recentemente órgãos governamentais, como o Ministério do Trabalho e Emprego (BRASIL, 2007), focalizava essencialmente no indivíduo, conceituando a deficiência como uma limitação 
física, mental, sensorial ou múltipla que incapacita ou limita a pessoa que se encontra nessa condição para o exercício de atividades normais da vida. Em função disso, o indivíduo apresenta dificuldades de se inserir nas mais variadas instâncias sociais, dentre elas as organizações e instituições que se configurem como campos de atuação profissional.

Destarte, no Brasil, a preocupação em entender e reconhecer os direitos desse segmento, fixando normas específicas é relativamente nova, ocorrendo principalmente após a promulgação da Constituição Federal de 1988. Não é de se estranhar, portanto, que as sociedades ainda atrelem às pessoas com deficiência sentimentos de caridade e filantropia, não acreditando nas suas possibilidades produtivas. Em complementaridade, Bahia (2006), Correr (2010), Figueira (2015) e Toldrá, Marque e Brunello (2010) relatam que tanto a desinformação sobre as deficiências, como a inadequação das condições arquitetônicas, de transporte e de comunicação ainda persistem. Em detrimento disso, pessoas capazes e produtivas acabam distantes do convívio social e dos ambientes de trabalho.

É possível verificar, então, que a discussão em torno dessa temática tem ganhado destaque e reconhecimento e, nesse direcionamento, Assunção, Carvalho-Freitas e Oliveira (2015), Miranda (2006) e Schmidt e Del-Masso (2014) consideram que a política de cotas aprovada no Brasil se constituiu como um grande avanço dentre as iniciativas nacionais, promovendo a empregabilidade das pessoas com deficiência. Entretanto, apesar da efetivação de políticas afirmativas, verifica-se que a inclusão desse público no mundo do trabalho ocorre a passos lentos, evidenciado que é necessário adotar outras medidas para que as organizações sejam de fato inclusivas (Correr, 2010; Vieira, Vieira, \& Francischetti, 2015).

Ainda assim, a pesquisa realizada por Araújo e Schmidt (2006) aponta que grande parte das empresas participantes não consegue cumprir a Lei de Cotas, apesar de revelarem que a contratação se dê prioritariamente em decorrência do atendimento ao disposto na referida lei, mostrando-se como algo que ainda necessite de grande reflexão e reorganização das ações para seu estabelecimento.

Em uma análise geral, identifica-se que a Lei de Cotas busca promover a participação das pessoas com deficiência no mercado de trabalho. Seu texto, contudo, deixa de descrever ações que viabilizem a sua permanência. Mesmo que seu direito de acesso ao campo laboral esteja assegurado, o caminho a ser percorrido ainda é extenso, complexo e exige a compreensão de diversas variáveis que exercem influência nesse processo. Nesse sentido, podemos refletir sobre o fato de que, muito embora se busque, no Brasil, realizar a inclusão desse segmento no mercado de trabalho, o que se tem ainda é um processo de inserção (Camargo, 2014), ou seja, um encaminhamento para que se promova a real participação dessas pessoas nos contextos organizacionais. Isso só parece ser possível de se experimentar em larga escala, quando as organizações de trabalho estiverem aptas a promover, com base em seus processos de mudança - sobretudo de cultura organizacional - a permanência desses trabalhadores em seus postos de trabalho, com reais possibilidades de participação, que garantam inclusive o desenvolvimento de carreiras e o assumir de postos de liderança e de gestão nas organizações (Camargo, 2014).

Desconstruir a imagem do indivíduo deficiente como incapaz, improdutivo, lento, desprovido de qualidades e oneroso, e criar o conceito de um indivíduo capaz, produtivo, dotado de qualificação profissional, é um trabalho árduo e lento, que deve ser compreendido como um compromisso social de diversos profissionais - incluindo-se aqui o POT - quando se pensa em promover condições mais igualitárias para o desenvolvimento humano e, consequentemente, criar condições para que o contexto o aceite e o qualifique, favorecendo o estabelecimento de interações sociais entre pares não análogos, ou melhor, de pessoas com e sem deficiência.

\section{Considerações sobre a identidade e o papel do POT diante do tema "deficiência e trabalho"}

As adequações necessárias a serem realizadas, visando promover de fato a participação de pessoas com deficiência no mercado de trabalho e, portanto, nas organizações de trabalho, ainda são muitas e complexas, o que sugere uma demanda maior de tempo para que ocorram em sua totalidade. Muitos aspectos dos contextos de trabalho precisam ser adequados (clima organizacional, cultura organizacional, barreiras arquitetônicas, instrumentais e comportamentais, metodologias de gestão e avaliação do desempenho humano no trabalho, formas de se recrutar, selecionar, treinar etc.), e a maioria das organizações vem encontrando diversas dificuldades ao iniciarem esse processo 
(Camargo, 2014; Dota, 2015; Schimidt, \& Del-Masso, 2014; Vieira, Vieira, \& Francischetti, 2015).

Segundo Araújo e Schmidt (2006) e Dota (2015), as instituições especializadas no atendimento às $\mathrm{PcD}$ e as próprias empresas ainda encontram muitas dificuldades em estabelecer um diálogo produtivo que realmente viabilize a inclusão de PcD no mercado de trabalho. Por um lado, empresas apontam a baixa escolaridade, a falta de qualificação e a pouca quantidade de pessoas disponíveis para a ocupação dos postos exigidos pela Lei de Cotas (Dota, 2015; Schimidt, \& Del-Masso, 2014). Por outro, instituições voltadas para o atendimento das pessoas com deficiência reclamam da falta de tolerância, solidariedade, paciência e preparo por parte dos profissionais atuantes nas organizações.

A princípio, como mostrado em pesquisas (Bahia, 2006; Carvalho-Freitas, 2007; 2009; Correr 2010; Dota 2015; Simas, Souto, \& Carvalho-Freitas, 2014; Violante, \& Leite, 2011), muitas empresas apenas passaram a contratar pessoas com deficiência devido à legislação de cotas vigente, objetivando a evitação de multas ou outras formas de punição, sem buscar, portanto, compreender as reais possibilidades, potencialidades e dificuldades apresentadas por esses sujeitos, e como elas poderiam contribuir para o desenvolvimento de seu empreendimento; o que tem, em síntese, culminado em práticas de inserção e não da sua real participação, como afirma Camargo (2014).

Em particular, na pesquisa realizada com profissionais de recursos humanos, Violante e Leite (2011) relatam que cabe ao psicólogo inserido nos contextos organizacionais e de trabalho auxiliar na desconstrução de uma imagem negativa comumente veiculada do indivíduo deficiente. Contudo, os autores reconhecem que esse é um processo custoso e lento, a ser empreendido " $[. .$.$] como um compromisso social de diversas$ áreas, quando se pensa em promover condições mais igualitárias para o desenvolvimento humano e consequentemente criar condições para que o contexto o qualifique" (p. 75); tal posição é corroborada por Vieira, Vieira e Francischetti (2015) ao afirmarem:

no contexto empresarial, o psicólogo pode atuar nos setores de recursos humanos, desde a sensibilização dos gerentes para a importância da contratação de pessoas com deficiência, que apresentem potencial para o compromisso social, o que reflete em uma imagem positiva no mercado de trabalho, além de contribuir para uma sociedade mais inclusiva, bem como sobre as potencialidades das pessoas com deficiência, singulares a cada sujeito e que podem agregar valores à instituição, pelo próprio convívio com a diversidade (p. 360).

Mas, seria mesmo esse o papel do POT ou um de seus papéis? Tal responsabilidade pode mesmo ser entendida como pertinente ao escopo de suas atribuições, possuindo nexo relacional com sua identidade científico-profissional? Senão vejamos.

Há um documento do Conselho Federal de Psicologia (CFP), intitulado "Atribuições Profissionais do Psicólogo no Brasil" em que, sobre a atuação mais generalista do psicólogo, se lê: "o Psicólogo, dentro de suas especificidades profissionais, atua no âmbito da educação, saúde, lazer, trabalho, segurança, justiça, comunidades e comunicação com o objetivo de promover, em seu trabalho, o respeito à dignidade e integridade do ser humano" (CFP, 1992, p. 1, grifo nosso). Neste mesmo documento o CFP, define as atribuições do POT ao longo de 20 pontos (que obviamente não poderemos aqui reproduzir integralmente) e de forma preambular afirma que este profissional:

atua individualmente ou em equipe multiprofissional, onde quer que se deem as relações de trabalho nas organizações sociais formais ou informais, visando a aplicação do conhecimento da Psicologia para a compreensão, intervenção e desenvolvimento das relações e dos processos intra e interpessoais, intra e intergrupais e suas articulações com as dimensões política, econômica, social e cultural (CFP, 1992, p. 3).

Gostaríamos de poder parar aqui e dizer que somente a interpretação crítica destes dois excertos seria suficiente para afirmar que, estando um POT presente na organização de trabalho, passa a ser, por óbvio, sua responsabilidade atuar em prol da inclusão de pessoas com deficiência, com vistas a garantir condições para a sua empregabilidade; não obstante ao fato de atuar, possivelmente, em equipe multiprofissional e de forma interdisciplinar. Mas é possível verificar ainda, de forma complementar, e para enriquecer a aqui iniciada discussão, que, como representante de uma especialidade da Psicologia - a Psicologia Organizacional e do Trabalho - cuja tarefa central ou missão 
pode ser sintetizada em "[...] explorar, analisar e compreender como interagem as múltiplas dimensões que caracterizam a vida das pessoas, dos grupos e das organizações [...]" com a “[...] finalidade de construir estratégias e procedimentos que possam promover, preservar e restabelecer a qualidade de vida e o bem-estar das pessoas" (Zanelli, \& Bastos, 2004, p. 490), o POT não pode se furtar à inerente obrigação de ser o agente de planejamento e execução das ações que, nos contextos de sua atuação, implicariam na promoção da inclusão das pessoas com deficiência. Isso posto, para além da obrigatoriedade da ação afirmativa - Lei de Cotas, este profissional deve reconhecer a importância do trabalho para a vida e desenvolvimento de qualquer pessoa, além de contribuir para o desenvolvimento social, político e econômico da sociedade.

Suas ações devem auxiliar nos processos de elaboração de intervenções, sobretudo diagnósticas e educativas, que viabilizem o acesso e a permanência das pessoas com deficiência nos contextos laborais. Dessa maneira, a atuação do POT deve coadunar com a eliminação das barreiras na esfera organizacional, promovendo ações de acessibilidade nos seus mais diferentes âmbitos: comunicacional (meios e formas diferenciadas de comunicação entre as pessoas), metodológico (métodos e/ou estratégias diferentes que visem a apropriação de conhecimentos), instrumental (oferta de equipamentos, instrumentos, ferramentas, utensílios em atendimento a condições diversas), programática (promulgação e efetivação de políticas públicas, legislações, normas que orientem e garantam a participação de todos nas diversas instâncias) e atitudinal (supressão de preconceitos, estereótipos, estigmas e discriminações nos comportamentos da sociedade para pessoas que têm deficiência), definidas por Sassaki (2009). Em especial, o POT, pela sua formação, deve sensibilizar e capacitar o público interno das organizações de trabalho (trabalhadores de um modo geral, gestores, terceiros etc.) no trato profissional com essas pessoas, desvelando peculiaridades e mitos sobre determinadas deficiências. As práticas iniciais também pressupõe: a análise das atividades a serem desempenhas pelas pessoas com deficiência, considerando as condições de acessibilidade postas; a função/cargo a ser ocupado; análise das especificidades da condição laboral a ser ofertada em detrimento dos prejuízos impostos pela deficiência; capacitação profissional; elaborar a reestruturação e enriquecimento de cargos considerando as atividades a serem realizadas e levando em consideração todos os trabalhadores; planejar e executar ações educativas e de sensibilização, sobretudo com profissionais que atuam como gestores e/ou responsáveis por setores ou pela organização; elaborar estratégias de diagnósticos contínuos referentes à relação entre essas pessoas e as atividades profissionais, visando identificar e atuar sobre dificuldades e necessidades de aprimoramentos; atuar como mediador entre os trabalhadores para o convívio com as diferenças, lembrando que todos têm direito a participar do mundo do trabalho; entre outras ações. É igualmente interessante que esse profissional busque instrumentos que possibilitem o acompanhamento e avaliação crítica e contínua das intervenções colocadas em prática para que, dessa forma, melhorias possam ser constantemente alcançadas em benefício de todos os trabalhadores, independentemente de terem ou não alguma deficiência.

Sabe-se que tais medidas são complexas e exigem esforços para sua efetivação, sobretudo, considerando-se a relação atual do capital com o trabalho, em que o objetivo maior é a produção com baixo custo e a busca quase insana pela produtividade desejada e vantagens econômicas.

A título de exemplo no que se refere ao processo de sensibilização dos gestores e demais trabalhadores, é oportuno que tal ação ocorra antes do ingresso da pessoa com deficiência, uma vez que se caracteriza como uma oportunidade de aquisição de novos conhecimentos com relação aos conceitos, aos aspectos legais, sociais e individuais, se configurando como um espaço de discussão crítica sobre a temática no desvelamento de preconceitos infundados. Tal medida favorece a conscientização do coletivo organizacional sobre as potencialidades, competências e habilidades da pessoa com deficiência, incidindo no fato de que auxilia os demais trabalhadores a não enfatizar os prejuízos decorrentes das limitações do indivíduo deficiente, mas sim em promover ajustes que possam minimizá-los.

Ações dessa natureza mostram-se necessárias, pois o modo como os empregadores irão interpretar a deficiência determinará o foco da sua atenção em relação às tarefas de trabalho que vão ser direcionadas a esses sujeitos. Contudo, ainda se observam descréditos em relação a real capacidade desse segmento para o trabalho e, em consequência, as funções que as pessoas com deficiência têm ocupado são aquelas de natureza mais simples, muitas vezes sem grande contato com público e que exigem pouca qualificação profissional. 
Isso ocorre, em grande parte, em função do foco do empregador dirigir-se para os prejuízos/dificuldades visíveis. Nessa direção, lhes são ofertadas funções supostamente compatíveis com a deficiência apresentada. Esse raciocínio é corroborado por Correr (2010) e Omote (1996) quando afirmam que a sociedade, ao conceber as dificuldades desse segmento como advindas de suas limitações orgânicas, adota medidas para inseri-las no mercado de trabalho baseadas na natureza da deficiência e não nas potencialidades presentes ou passíveis de serem desenvolvidas, favorecendo com que a culpa de qualquer insucesso que possa vir a ocorrer com essa população no ambiente de trabalho acabe sempre recaindo sobre o indivíduo, e não nas condições que foram disponibilizadas a ele.

O trabalho então se torna alienado e desmotivador, a partir do momento em que não permite ao homem se ver como força produtiva importante para as relações do trabalho, podendo acarretar em insatisfação e baixo comprometimento profissional.

A relevância do papel do POT nas organizações, com a função de orientar o coletivo organizacional, é validada a partir de estudos sobre Gestão de Pessoas e comportamento organizacional que indicam principalmente três dificuldades para inserir e gerir o trabalho dessas pessoas, quais sejam: as formas como os gestores veem a deficiência, a adequação das condições e práticas de trabalho por parte das organizações e a necessidade de avaliar a satisfação das pessoas com deficiência inseridas no mercado (Assunção, Carvalho-Freitas, \& Oliveira, 2015; Carvalho-Freitas, Marques, \& Almeida, 2009; Vieira, Vieira, \& Francischetti, 2015;).

Tais aspectos podem ser desmembrados, gerando diversos outros pontos de dificuldade, como a adequação das formas de trabalho, que inclui desde práticas da função em si até adequações nas práticas relacionadas à Gestão de Pessoas, como por exemplo, estratégias adequadas de recrutamento e seleção, programas de gestão e avaliação de desempenho, programas de treinamento, desenvolvimento e educação para o trabalho (TD\&E), ações contínuas de levantamento de demandas e necessidades, favorecimento de espaços de discussão e diálogo franco com a participação de pessoas com e sem deficiência, entre outros.

Com relação a essa questão, segundo o Instituto Ethos (2009), existem alternativas que podem auxiliar na implantação de medidas inclusivas, como a identificação das funções ocupacionais existentes, dos cri- térios mais adequados para a contratação e requisitos necessários para o exercício das funções e a adoção de programas de contratação, definindo atribuições e treinando ao profissional para que ele seja produtivo. Também algumas oficinas e cursos de capacitação, existentes nos centros de reabilitação profissional, têm como objetivo a simulação do ambiente real de trabalho, proporcionando condições para aquisição de conhecimentos e desenvolvimento de comportamentos que irão favorecer o ingresso no mercado de trabalho. Além disso, segundo Dota (2015), a própria organização pode oferecer a capacitação por intermédio de convênios com programas dessa natureza disponíveis e/ou assessorias ou mesmo programar projetos de treinamento da pessoa com deficiência para exercício da função dentro da própria organização.

Dota (2015), Schmidt e Del-Masso (2014) e Tanaka e Manzini (2005), e ainda apresentaram em seus estudos o papel importante das instituições especiais dentro desse processo, tendo em vista que muitas delas mantêm setores que se propõem a qualificar esses sujeitos para encaminhá-las ao mercado de trabalho. Para isso, há que se pensar que elas precisariam manter contato permanente com as organizações, conhecer quais são suas reais necessidades e, então, oferecer cursos de qualificação compatíveis com as necessidades do mercado de trabalho sem, contudo, retirar a responsabilidade das organizações nesse processo. Sendo assim, canais abertos entre as organizações e com essas instituições que trabalham preparando-as para o mercado de trabalho, configura-se como uma intervenção importante e necessária que poderia ser coordenada pelo POT.

Cabe ainda ao POT se atentar aos fatores externos da vida cotidiana das pessoas com deficiência, uma vez que influenciam sobremaneira sua participação no mercado de trabalho, quais sejam: transporte não adaptado; falta de oportunidades de aperfeiçoamento educacional e/ou profissional; pouca oferta de serviços especializados de educação e saúde, além de barreiras sociais causadas pelo desconhecimento das deficiências e doenças por parte da população em geral, o que gera mitos, preconceitos e rejeição.

No âmbito da equipe multiprofissional responsável pelas políticas e práticas de Gestão de Pessoas nas organizações de trabalho, o POT tem (ou deveria ter) papel de destaque, posto que - como veremos a seguir - essa equipe nem sempre está preparada para atender e acompanhar as demandas atuais do mundo do trabalho, limi- 
tando-se, em muitos casos, a ações meramente administrativas, trabalhistas e legalistas (Camargo, 2014).

A título de exemplificação tem-se o estudo de Violante e Leite (2011), que realizaram uma pesquisa com trabalhadores do setor de recursos humanos de empresas de médio e grande porte de um município do oeste paulista, com a finalidade de examinar a empregabilidade das pessoas com deficiência, e constataram, no relato dos entrevistados, considerações interessantes: a) apesar da tentativa dos entrevistados de contextualizarem a deficiência enquanto visível em determinados ambientes de trabalho, na execução de determinadas atividades, ainda a concebem como limitada, incapaz de realizar determinadas atividades; b) o foco da deficiência ainda recai sobre o sujeito que a apresenta, pouco se atentando para adequações do espaço, no sentido de minimizar as limitações decorrentes da deficiência; c) percebem ser necessário atenção diferenciada, porém, os discursos denotam que os investimentos deveriam ser de ordem pessoal e não no contexto, reforçando ainda que o sujeito é diferente e em função disso necessita se adaptar; d) concebem o ambiente laboral com uma possível dificuldade para a inserção das PcD. Em estudo que objetivou avaliar os efeitos de uma intervenção que visou a reflexão crítica sobre a temática inclusão da pessoa com deficiência no universo do trabalho, realizado com funcionários e gestores de uma instituição de ensino superior por Vilela e Leite (2017), foi possível identificar, pela aplicação do Inventário de Concepções sobre Deficiência (Carvalho-Freitas, 2007), que os participantes, após terem frequentado o curso, manifestaram concepções mais favoráveis à participação da pessoa com deficiência no trabalho. Isso vem reforçar que o profissional da área de Psicologia pode, em muito, atuar como facilitador para que a pessoa com deficiência possa participar no universo do trabalho, uma vez que é habilitado para atuar com grupos interventivos e preparado para discutir assuntos e situações passíveis de preconceitos e de atitudes discriminatórias dirigidas a grupos desfavorecidos e excluídos socialmente de forma crítica e fundamentada. Nessa direção, destaca-se a atuação da Universidade, que assume importante papel na disseminação das produções acadêmicas, alavancando o conhecimento científico e disponibilizando-o para o favorecimento de práticas sociais mais assertivas, como no caso do trato à pessoa com deficiência e temas correlacionados, enquanto um espaço formador de conhecimentos específicos e opinião crítica (Camargo, Goulart Junior, Cardoso, \& Feijó, 2015).

\section{Considerações finais}

Ao longo deste ensaio, dissertamos sobre a pessoa com deficiência e suas formas de tratamento na história, com a finalidade de justificar os motivos pelos quais esta parcela da população ainda tem sido alvo de preconceitos e de tratamentos discriminatórios na sociedade. Além disso, apresentamos panoramicamente o cenário atual da inclusão da pessoa com deficiência no trabalho, em especial, destacando as mudanças ocorridas no Brasil após a promulgação da Lei de Cotas, 1991, com o objetivo de demonstrar as motivações que as organizações passaram a ter quando buscam contratar este público. Em seguida, abordamos aspectos da identidade do psicólogo, em especial do POT, e aspectos relativos a seu processo formativo e de exercício profissional, de forma que, assim, se presentificasse no texto as condições e formas de atuação deste profissional frente ao tema "inclusão da pessoa com deficiência no trabalho".

Neste momento, e encaminhando nosso ensaio para o final, apresentamos nossas considerações propositivas, contendo algumas reflexões sob a forma de desafios lançados ao processo formativo e de exercício da profissão do psicólogo junto às pessoas com deficiência nas organizações de trabalho, posto que consideramos ser, seu ainda tímido envolvimento com a temática, um dos obstáculos presentes no contexto.

As pesquisas acessadas por meio da revisão de literatura que fundamentou nossas reflexões, evidenciam o fato de que as pessoas com deficiência se deparam com inúmeras barreiras nos contextos de trabalho, pois ainda se faz presente na cultura brasileira, com reflexos nas culturas organizacionais, uma série de preconceitos que, somados ao despreparo das organizações e de seus gestores, acentuam as dificuldades de permanência no trabalho.

Como a ação afirmativa do Estado - Lei de Cotas não garante a permanência das pessoas com deficiêncianoscontextos detrabalho, somente sua contratação, as organizações precisam se adaptar para mantê-las e este tem sido um ponto frágil na relação, sinalizando para a complexidade do contexto, assim constituído até o momento: as organizações de trabalho contratam pessoas com deficiência para atender as exigências da legislação e evitar as ações punitivas dela decorrentes, mas não necessariamente compreenderam ou implementaram programas de integração social dessa população em suas estruturas, permitindo ainda, ou não enfrentando eficazmente, a exis- 
tência de barreiras arquitetônicas e atitudinais que dificultam a inclusão, ou seja, como refletido neste ensaio, vivemos ainda um momento em que se tem praticado a "inserção" e não a "inclusão" das pessoas com deficiência no mercado de trabalho brasileiro.

O despreparo das organizações, e de seus respectivos gestores, para o efetivo enfrentamento dos processos demandados para a realização, de fato, da inclusão de pessoas com deficiência no trabalho, aqui apontado, pode ser minimizado pela atuação do POT neste contexto.

As possibilidades de atuação do POT para a promoção da inclusão das pessoas com deficiência são inúmeras, incluindo desde intervenções com o coletivo organizacional, ações diretas com os que atuam no ambiente de trabalho, ações externas junto a outras instituições formadoras, e com a comunidade em geral, desde que seu exercício profissional se volte para desenvolver pessoas com vistas a favorecer seu pleno exercício da cidadania. Assim, para a ampla e adequada atuação dos psicólogos nesses contextos, faz-se necessário que haja também uma formação teórica, científica e ética sólidas por parte dos mesmos, participando e fomentando ativamente o debate de ideias, favorecendo respostas de segmentos variados que promovam a inclusão social de demandas populacionais marginalizadas. Neste sentido, é preciso destacar a existência da Portaria no 1.793, de 28 de dezembro de 1994 (BRASIL, 1994), do Ministério da Educação e do Desporto, que dispõe sobre a necessidade de complementar os currículos de formação de docentes e outros profissionais que interagem com pessoas com deficiência.

Sabe-se das dificuldades e limitações que o psicólogo terá para atuar na direção anteriormente descrita, sobretudo porque, na maioria das organizações de trabalho na atualidade, os valores econômicos se sobrepõem aos valores humanos. No entanto, o POT, mediante ações estratégicas e juntamente com uma equipe multidisciplinar, pode propor intervenções que venham ao encontro do atendimento dos interesses, tanto das organizações, como dos trabalhadores, nas quais ambos possam sair favorecidos.

Nesse sentido, entende-se que a Lei de Cotas, atrelada a outras recomendações normativas, se configura ainda como necessária para o desenvolvimento inicial de práticas inclusivas, pois promove a garantia da oportunidade de indivíduos, considerados incapazes e por longos anos segregados do convívio comum, se inserirem no mercado de trabalho.
Contudo, para que a inclusão não se restrinja à oportunidade de acesso, ou seja, para que não se resuma à simples inserção, são necessárias mudanças estruturais nas relações de trabalho, sem as quais a aplicabilidade das medidas previstas teria apenas efeito paliativo. Ressalta-se aqui a necessidade cada vez maior do desenvolvimento de pesquisas voltadas à compreensão e análise da nova realidade profissional no interior das organizações de trabalho, tanto na avaliação e questionamento das práticas existentes quanto para aventar e inventar novas possibilidades.

Para tanto, algumas práticas em Psicologia Organizacional e do Trabalho e Gestão de Pessoas são possíveis, por exemplo, ao realizar a análise dos cargos e funções da organização, adequar as atividades e os cargos às mais diversas pessoas que podem ocupá-los; adequar o processo de recrutamento e seleção, para possibilitar a participação de todos que se interessarem; e, principalmente, trabalhar a sensibilização e conscientização do coletivo organizacional no acolhimento de qualquer trabalhador, incluindo aquele que apresenta diferenças físicas, sensoriais e/ou comportamentais. Recentemente, o CFP, por meio de Ofício Circular no 0047-13/RT-CFP, de 19 de fevereiro de 2013, endereçado a todos os coordenadores de cursos de Psicologia em nível de graduação e pós-graduação, emitiu a Nota Técnica "Construção, adaptação e validação de instrumentos para pessoas com deficiência", com o objetivo de orientar os profissionais de Psicologia que realizam avaliação psicológica para esse público, sobretudo no que se refere à utilização de testes psicológicos (CFP, 2013). O documento visa orientar a construção, adaptação e validação de instrumentos para pessoas com deficiência.

Sabe-se, entretanto, que cada organização tem suas particularidades e sua identidade própria e, sendo assim, há que se tentar várias estratégias que favoreçam a participação da pessoa com deficiência no contexto organizacional. Sugere-se que o POT, a partir de uma sólida formação, possa fazer uma leitura adequada do contexto organizacional em que está inserido, identificando aspectos fundamentais, sobretudo da cultura organizacional predominante, que influenciam na forma como as pessoas se comportam dentro dos contextos de trabalho. Dessa maneira, sua atuação deve partir de um diagnóstico amplo e crítico, capaz de identificar quais as melhores estratégias para se iniciar ou consolidar as ações a serem implantadas nos seus postos de trabalho e na organização como um todo. 
Referindo-se à formação dos psicólogos, ela precisa garantir que esses profissionais desenvolvam o domínio dos conhecimentos psicológicos necessários para o seu trabalho, sempre pautado no compromisso técnico, científico e ético. Faz-se importante também que esses profissionais desenvolvam competências que favoreçam um desempenho profissional de qualidade, sempre em direção ao bem-estar, saúde e qualidade de vida das pessoas com as quais interagem profissionalmente e, nesse contexto, práticas que visem a participação de pessoas com deficiência no trabalho precisam ganhar destaque na atualidade.

Pelo acima exposto, depreende-se que a concretização de políticas públicas na área da inclusão das pessoas com deficiência é tarefa árdua que envolve a participação da sociedade como um todo, pois é nela que as mudanças são realmente efetivadas e o POT muito tem a contribuir.

Estamos, ainda, engatinhando quando se trata de ações e políticas de inclusão que garantam a participação das pessoas com deficiência no mundo do trabalho e, principalmente, na identificação de práticas de Gestão de Pessoas que venham favorecer esse processo, e sendo assim, esse texto encontra-se distante de esgotar o assunto. Entretanto, entende-se que ele possa trazer contribuições na direção de fomentar a reflexão dos profissionais da Psicologia, em especial da Psicologia Organizacional e do Trabalho, e de outros que atuam com Gestão de Pessoas, para que o universo das organizações seja de fato inclusivo.

\section{Referências}

Amiralian, M. L. T. M. (1986). Psicologia do excepcional (Coleção Temas Básicos de Psicologia, v. 8). São Paulo, SP: EPU.

Aranha, M. S. F. (2001). Paradigma da relação da sociedade com as PcD. Revista do Ministério Público do Trabalho, 11(21), 160-173. Recuperado de http://www.adiron.com.br/arquivos/paradigmas.pdf

Araújo, J. P., \& Schmidt, A. (2006). A inclusão de pessoas com necessidades especiais no trabalho: a visão de empresas e de instituições educacionais especiais na cidade de Curitiba. Revista Brasileira de Educação Especial, 12(2), 241-254. https://doi.org/10.1590/S1413-65382006000200007

Assunção, R. V., Carvalho-Freitas, M. N., \& Oliveira, M. S. (2015). Satisfação no trabalho e oportunidades de desenvolvimento da carreira entre profissionais com deficiência. Revista Psicologia Organizações e Trabalho, 15(4), 340-351. https://doi.org/10.17652/rpot/2015.4.556

Bahia, M. S. (2006). Responsabilidade social e diversidade nas organizações: contratando pessoas com deficiência. Rio de Janeiro, RJ: Qualitymark.

Bernal, A. O. (2010). Psicologia do trabalho: como enfrentar o assédio psicológico e o estresse no trabalho. Porto Alegre, RS: Artmed.

Bittencourt, Z. Z. L. C., \& Fonseca, A. M. R. (2011). Percepções de pessoas com baixa visão sobre seu retorno ao mercado de trabalho. Paidéia (Ribeirão Preto), 21(49), 187-195.https://doi.org/10.1590/S0103-863X2011000200006

Borges, L. O., \& Yamamoto, O. H. (2004). O mundo do trabalho. In J. C. Zanelli, J. C. Borges-Andrade, \& A. V. B. Bastos (Orgs.). Psicologia, organizações e trabalho no Brasil (pp. 24-62). Porto Alegre, RS: Artmed.

Brasil. (1999, 21 dez.). Decreto no 3.298, de 20 de dezembro de 1999. Regulamenta a Lei no 7.853 de 24 de outubro de 1989, que dispõe sobre a Política Nacional para a Integração da Pessoa Portadora de Deficiência, consolida as normas de proteção e dá outras providências. Diário Oficial da União.

Brasil. (2009, 26 ago.). Decreto no 6.949, de 25 de agosto de 2009. Promulga a Convenção Internacional sobre os Direitos das Pessoas com Deficiência e seu Protocolo Facultativo, assinados em Nova York, em 30 de março de 2007. Diário Oficial da União.

Brasil. (1990, 19 abr.). Lei no 8.112, de 11 de dezembro de 1990. Dispõe sobre o Regime Jurídico dos Servidores Públicos Civis da União, das autarquias e das fundações públicas federais. Diário Oficial da União.

Brasil. (1991, 25 jul.). Lei n 8.213, de 24 de julho de 1991. Dispõe sobre os Planos de Benefícios da Previdência Social e dá outras providências. Diário Oficial da União.

Brasil. (2015, 7 jul.). Lei n 13.146, de 6 de julho de 2015. Institui a Lei Brasileira de Inclusão da Pessoa com Deficiência (Estatuto da Pessoa com Deficiência). Diário Oficial da União. 
Psicologia: Ciência e Profissão Jul/Set. 2017 v. 37 n³, 799-814.

Brasil. (2007). Ministério do Trabalho e Emprego. A inclusão das PcD no mercado de trabalho (2a ed.). Brasília, DF: o autor. Recuperado de http://www.acessibilidade.org.br/cartilha_trabalho.pdf

Brasil. (1994, 28 dez.). Portaria no 1.793, de 28 de dezembro de 1994. Dispõe sobre a necessidade de complementar os currículos de formação de docentes e outros profissionais que interagem com portadores de necessidades especiais e dá outras providências. Diário Oficial da União.

Camargo, M. L. (2014). O papel da psicologia organizacional e do trabalho no enfrentamento dos desafios à inclusão de pessoas com deficiência no mercado de trabalho. Mimesis - Ciências Humanas, 35(2), 201-222. Recuperado de http://www.usc.br/biblioteca/mimesis/mimesis_v35_n2_2014_art_03.pdf

Camargo, M. L., Goulart Júnior, E., Cardoso, H. F., \& Feijó, M. R. (2015). Projeto de extensão "Pessoas com Deficiência e Mercado de Trabalho - desafios à inclusão": desvelando distâncias entre os discursos e as práticas. Revista Raízes e Rumos, 3(1), 79-92. Recuperado de http://www.seer.unirio.br/index.php/raizeserumos/article/view/5109/4605

Carvalho-Freitas, M. N. (2007). A inserção de PcD em empresas brasileiras - um estudo sobre as relações entre concepções de deficiência, condições de trabalho e qualidade de vida no trabalho (Tese de doutorado). Universidade Federal de Minas Gerais, Belo Horizonte.

Carvalho-Freitas, M. N. (2009). Inserção e gestão do trabalho de pessoas com deficiência: um estudo de caso. Revista de Administração Contemporânea, 13(spe), 121-138. https://doi.org/10.1590/S1415-65552009000500009

Carvalho-Freitas,M.N.,\&Marques,A.L. (2009).Pessoascomdeficiênciaetrabalho:percepçãodegerentesepós-graduandos em Administração. Psicologia: Ciência e Profissão, 29(2), 244-257. https://doi.org/10.1590/S1414-98932009000200004

Carvalho-Freitas, M. N., Marques, A. L., \& Almeida, L. A. D. (2009). Pessoas com Deficiência: comprometimento organizacional, condições de trabalho e qualidade de vida no trabalho. Gerais: Revista Interinstitucional de Psicologia, 2(2), 92-105. Recuperado de http://www.ufsj.edu.br/portal2-repositorio/File/incluir/artigo_6.pdf

Conselho Federal de Psicologia - CFP. (1992). Atribuições profissionais do Psicólogo no Brasil: contribuição do Conselho Federal de Psicologia ao Ministério do Trabalho para integrar o catálogo brasileiro de ocupações. Brasília, DF: o autor. Recuperado de http://site.cfp.org.br/wp-content/uploads/2008/08/atr_prof_psicologo.pdf

Conselho Federal de Psicologia - CFP. (2013). Nota técnica: Construção, adaptação e validação de instrumentos para $P c D$. Brasília, DF: o autor. Recuperado de http://site.cfp.org.br/documentos/nota-tecnica-construcao-adaptacao-e-validacao-de-instrumentos-para-pessoas-com-deficiencia/

Correr, R. (2010). Representações compartilhadas sobre emprego e deficiência. Curitiba, PR: CRV.

Del Prette, A., \& Del Prette, Z. A. P. (2008). Psicologia das relações interpessoais: vivências para o trabalho em grupo (7a ed.). Petrópolis, RJ: Vozes.

Dota, F. P. (2015). Inclusão da pessoa com deficiência intelectual no mercado de trabalho: avaliação de um programa de capacitação profissional (Dissertação de mestrado). Faculdade de Ciências da Universidade Estadual Paulista "Júlio de Mesquita Filho", Bauru, SP.

Figueira, E. (2015). Psicologia e inclusão: atuações psicológicas em pessoas com deficiência. Rio de Janeiro, RJ: Wak.

Hansel, T. D. (2009). A empregabilidade de pessoas com deficiências: possibilidades e limitações (Monografia de Conclusão de Curso). Instituto Federal de Educação, Ciência e Tecnologia de Mato Grosso, Cuiabá, MT.

Instituto Brasileiro de Geografia e Estatística - IBGE. (2010). Censo 2010. Recuperado de http://censo2010.ibge.gov.br/.

Instituto Ethos (2009). Manual de incorporação dos critérios essenciais de responsabilidade social empresarial. São Paulo, SP: o autor.

Marques, C. A. (1998). Implicações políticas da institucionalização da deficiência. Educação \& Sociedade, 19(62), 105-122. https://doi.org/10.1590/S0101-73301998000100006

Miranda, T. G. (2006). Trabalho e deficiência: velhos desafios novos caminhos. In E. J. Manzini (Org.), Inclusão e acessibilidade (pp. 159-170). Marília: ABPEE.

Nascimento, E. S., \& Miranda, T. G. (2007). O trabalho e a profissionalização das pessoas com deficiência. Revista Faced, 12, 169-184. Recuperado dehttp://www.portalseer.ufba.br/index.php/entreideias/article/view/2761/1949

Organização dos Estados Americanos - OEA. (1999). Decreto № 3.956, de 8 de outubro de 2001. Promulga a Convenção Convenção Interamericana para a Eliminação de Todas as Formas de Discriminação contra as Pessoas Portadoras de Deficiência. Recuperado de http://portal.mec.gov.br/seesp/arquivos/pdf/guatemala.pdf 
Organização Internacional do Trabalho - OIT. (1983). C159 - Reabilitação Profissional e Emprego de Pessoas Deficientes. Recuperado ede http://www.ilo.org/brasilia/convencoes/WCMS_236165/lang--pt/index.htm

Omote, S. (1996). Deficiência e não-deficiência: recortes do mesmo tecido. Revista Brasileira de Educação Especial, 2(1), 65-73. Recuperado de http://www.abpee.net/homepageabpee04_06/artigos_em_pdf/revista2numerolpdf/r2_art06.pdf

Omote, S. (2008). Inclusão escolar: as contribuições da educação especial. São Paulo, SP: Cultura Acadêmica.

Puente-Palacios, K., \& Albuquerque, F. J. B. (2014). Grupos e equipes de trabalho nas organizações. In J. C. Zanelli, J. C. Borges-Andrade, \& A. V. B. Bastos (Orgs.), Psicologia, organizações e trabalho no Brasil (2a ed., pp. 385-412). Porto Alegre, RS: Artmed.

Rocha, M. S. (2000). O processo de inclusão na percepção do docente do ensino regular e especial (Monografia de conclusão de curso). Universidade Estadual de Londrina, Londrina, PR.

Sassaki, R. K. (2009). Inclusão: acessibilidade no lazer, trabalho e educação. Revista Nacional de Reabilitação (Reação), 12, 10-16. Recuperado de http://www.apabb.org.br/admin/files/Artigos/Inclusao\%20-\%20Acessibilidade\%20no\%20lazer,\%20trabalho\%20e\%20educacao.pdf

Schmidt, M. L. G., \& Del-Masso, M. C. S. (Orgs.). (2014). Readaptação profissional: da teoria à prática. São Paulo, SP: Cultura Acadêmica.

Simas, A. L. B., Souto, J. F., \& Carvalho-Freitas, M. N. (2014). Inclusão de pessoas com deficiência no trabalho: percepção dos universitários. Psicologia: Teoria e Prática, 16(3) 30-42. Recuperado de http://www.redalyc.org/ articulo.oa?id=193833500003

Tanaka, E. D. O., \& Manzini, E. J. (2005). O que os empregadores pensam sobre o trabalho da pessoa com deficiência? Revista Brasileira de Educação Especial, 11(2), 273-294. https://doi.org/10.1590/S1413-65382005000200008

Toldrá, R. C., Marque, C. B., \& Brunello, M. I. B. (2010). Desafios para a inclusão no mercado de trabalho de pessoas com deficiência intelectual: experiências em construção. Revista de Terapia Ocupacional, 21(2), 158-165. https:// doi.org/10.11606/issn.2238-6149.v21i2p158-165

Vieira, C. M., Vieira, P. M., \& Francischetti, I. (2015). Profissionalização de pessoas com deficiência: reflexões e possíveis contribuições da psicologia. Revista Psicologia Organizações e Trabalho, 15(4), 352-361. https://doi.org/10.17652/rpot/2015.4.612

Vilela, L. O., \& Leite, L. P. (2017). Effects of an intervention on the participation of people with disability in the workplace. Estudos de Psicologia (Campinas), 34(1), 185-195. https://doi.org/10.1590/1982-02752017000100018

Violante, R., \& Leite, L. P. (2011). A empregabilidade das pessoas com deficiência: uma análise da inclusão social no mercado de trabalho do município de Bauru, SP. Cadernos de Psicologia Social do Trabalho, 14(1), 73-91. https:// doi.org/10.11606/issn.1981-0490.v14ilp73-91

Zanelli, J. C., \& Bastos, L. O. (2004). Inserção profissional do Psicólogo em organizações e no trabalho. In J. C. Zanelli, J. C. Borges-Andrade, \& A. V. B. Bastos (Orgs.), Psicologia, organizações e trabalho no Brasil (pp. 466-491). Porto Alegre, RS: Artmed.

\section{Mário Lázaro Camargo}

Doutor, Unesp - Universidade Estadual Paulista “Júlio de Mesquita Filho”, Faculdade de Ciências, campus de Bauru. E-mail: mario.camargo@fc.unesp.br

\section{Edward Goulart Júnior}

Doutor, Unesp - Universidade Estadual Paulista "Júlio de Mesquita Filho", Faculdade de Ciências, campus de Bauru.E-mail: edward@fc.unesp.br

\section{Lúcia Pereira Leite}

Doutora, Unesp - Universidade Estadual Paulista "Júlio de Mesquita Filho", Faculdade de Ciências, campus de Bauru. E-mail: lucialeite@fc.unesp.br 
Endereço para envio de correspondência:

Universidade Estadual Paulista "Júlio de Mesquita Filho", Faculdade de Ciências, Departamento de Psicologia.

Av. Eng. Luiz Edmundo Carrijo Coube, 14-01, Bairro Vargem Limpa, CEP: 17033-360 - Bauru-SP

Recebido 24/08/2016

Reformulação 03/04/2017

Aprovado 26/06/2017

Received 08/24/2016

Reformulated $04 / 03 / 2017$

Approved 06/26/2017

Recebido $24 / 08 / 2016$

Reformulado 03/04/2017

Aceptado 26/06/2017

Como citar: Camargo, M. L., Goulart Júnior, E., \& Leite, L. P. (2017). O Psicólogo e a inclusão de pessoas com deficiência no trabalho. Psicologia: Ciência e Profissão, 37(3), 799-814. https://doi.org/10.1590/1982-3703003232016

How to cite: Camargo, M. L., Goulart Júnior, E., \& Leite, L. P. (2017). The Psychologist and the inclusion of people with disabilities at work. Psicologia: Ciência e Profissão, 37(3), 799-814. https://doi.org/10.1590/1982-3703003232016

Cómo citar: Camargo, M. L., Goulart Júnior, E., \& Leite, L. P. (2017). El Psicólogo y la inclusión de las personas con discapacidad en el trabajo. Psicologia: Ciência e Profissão, 37(3), 799-814. https://doi.org/10.1590/1982-3703003232016 